\title{
An analysis of different resources and programs supporting at-risk families in Spain
}

1. Hidalgo, Victoria PhD. Full professor. Department of Developmental and Educational Psychology. University of Seville (Spain). victoria@us.es.

https://orcid.org/0000-0002-9179-2722. Address: Facultad de Psicología. C/ Camilo José Cela, s/n, 41018, Sevilla, España. Tlfno. +34 954554332.

2. Pérez-Padilla, Javier. PhD. Full professor (jppadill@ujaen.es). Department of Psychology. University of Jaen (Spain).jppadill@ujaen.es https://orcid.org/0000-0003-2529-348X. Address: Campus las Lagunillas, s/n, 23071, Jaén, España.

3. Sánchez, Jose. Full professor. Department of Developmental and Educational Psychology. University of Seville (Spain).js@us.es

https://orcid.org/ 0000-0002-2368-6012. Address: C/ Camilo José Cela, s/n, 41018, Sevilla, España.

4. Ayala-Nunes, Lara. PhD. Full professor. Department of Psychology at the University of Warwick (UK). L.Ayala-Nunes@warwick.ac.uk https://orcid.org/0000-0001-5070-7731. Address: University Road, Coventry CV4 7AL, Coventry, UK.

5. Maya, Jesús. PhD student. Department of Developmental and Educational Psychology. University of Seville (Spain).jmaya3@us.es https://orcid.org/0000-0003-4472-1873. Address: C/ Camilo José Cela, s/n, 41018, Sevilla, España. 
6. Grimaldi, Víctor. PhD. Associate professor. Department of Developmental and Educational Psychology. University of Seville (Spain).vgrimaldi1@us.es

https://orcid.org/0000-0001-6286-1912. Address: C/ Camilo José Cela, s/n, 41018, Sevilla, España.

7. Menéndez, Susana. PhD. Full professor. Department of Social, Developmental and Educational Psychology. University of Huelva (Spain). menendez@dpsi.uhu.es https://orcid.org/0000-0003-2198-8006. Address: Avda. Tres de Marzo s/n, 21071, Huelva, España.

\begin{abstract}
The purpose of this research was to present an overview of the existing family support resources in Spain for at-risk families. We analysed 64 family support services from 16 agencies belong to 11 regions of Spain. In a second phase, 20 positive parenting programs were analysed in depth to ascertain the extent to which they met evidence-based program quality criteria. Our results suggest that services for at-risk families are delivered by public, local and social agencies. Most interventions were psycho-educational and aimed at parental training. The analysis of the positive parenting programs' quality showed both strengths and weaknesses. Most programs relied on a previous needs analysis and interventions were, to some extent, outlined in a manual. Nevertheless, few programs have been evaluated according to evidence-based program criteria. In light of these results, we discuss several practical implications for services and family support policies aimed at at-risk families.
\end{abstract}

Key words: Family support services; quality standards; evidence-based programs; positive parenting; at-risk families. 


\section{Introduction}

In the study of child development, there are two basic ideas over which there is currently broad consensus: one is that family is the context with most influence on development during childhood, and the other one is that many families need support to undertake their educational roles and responsibilities adequately. In this sense, the current vision of childhood and the family places the interests of children in the spotlight for social policies and lays the responsibility on governments to support fathers and mothers in their parenting roles and promote child well-being (Council of Europe, 2006; United Nations, 1989). Family support as a child welfare measure is a social priority for government bodies in most European countries, as the available evidence supports its effectiveness in promoting child well-being in disadvantaged family contexts (Gilbert, 2012). This paper presents a review of the resources currently available for supporting at-risk families in Spain, with a focus on the quality of positive parenting programs.

In relation to the importance of the family for child well-being, there is an important body of empirical evidence on the mechanisms through which different dimensions of socialization practices and family dynamic influence child development (e.g., Bornstein, 2015; Brooks, 2004; Fine \& Fincham, 2013). The robustness of this knowledge has led society to expect families to meet the needs of children through what is considered appropriate parenting behavior. Specifically, in Europe and as established in the Recommendation $\operatorname{Rec}(2006) 19$ on Policy to Support Positive Parenting, mothers and fathers are expected to exert positive parenting; in other words, promoting positive relations with their children. Parent-child relations should be based on the exercise of 
parental responsibility, guaranteeing children's rights, and promoting their development and well-being in the family setting. Thus, according to the principles of positive parenting, in order to encourage the holistic development of children, parental practices should be based on affection, support, communication, stimulation and structuring of routines, limits and rules setting, as well as on supporting and being involved in the daily lives of their sons and daughters (Daly, 2007; Daly et al., 2015).

However, not all families exercise positive parenting. Profound changes in society and within the family have meant that many parents find it hard to develop the competencies, knowledge and skills necessary to promote the healthy development of their children. In this paper, we consider at-risk families as those whom, for different reasons such as family crisis situations, stressful events, parental stress or lack of adequate parenting skills, cannot adequately meet the needs of their children, thereby hindering their development and well-being (Rodrigo, Byrne, \& Álvarez, 2012). Services and interventions offered to at-risk families have evolved greatly in recent years. From markedly assistance-based care, drawing on the deficit theory, it has evolved into more positive forms of intervention and action, focusing on family preservation by strengthening and optimizing how the family works in a more preventive approach (Chaffin, Bonner, \& Hill, 2001; Fraser \& Galinsky, 2004).

Current approaches to intervening with at-risk families focus on the strengths of the family, promoting parental competencies, fostering the personal and social development of the progenitors and expanding their sources of support and resources. They also put the emphasis on prevention, the need to promote family-practitioners cooperation, inter-institutional coordination and building up the natural and active resources of the community (Patterson, Chamberlain, \& Reid 2016; Rodrigo, Máiquez, Martín, \& Byrne, 2008; Spoth \& Redmond, 2000). The proposals stemming from 
research about the preventive and positive nature of interventions with at-risk families have been backed up by European policy recommendations for family support. Specifically, the Recommendation Rec(2006)19 states that local governments are responsible for developing preventive and psycho-educative family programs aimed at promoting positive parenting in situations of psychosocial risk (Council of Europe, 2006). In line with this, society is paying more attention to parental roles and the responsibilities of at-risk families, highlighting the need to attune interventions to specific family needs (Frost, Abbott, \& Race, 2015). This need to diversify family support services is at the top of the European agenda on child welfare (Council of Europe, 2011). In practical terms, this means following the principles of progressive universalism: support must be available for everybody, albeit with more support for those who need it most (Boddy, Smith, \& Statham, 2011).

Although there is currently a common framework in line with these recommendations, the evidence suggests that there is great diversity within family support initiatives in different countries (Molinuevo, 2013). Aspects such as the model of social policy, the characteristics of child protection systems, traditions in the organization of services and the amount of resources available in this area determine the common and distinctive features of family support initiatives in European countries. The variety of services, multi-level responsibility for support delivery and multi-agency coordination are the aspects in which we may observe more similarities, whist the differences are associated primarily with the drivers and the degree of parenting support universalization (Rodrigo, Almeida, \& Reichle, 2016). These differences have given rise to some countries holding a vision more based on child protection (e.g., Italy, Portugal, Spain) and others having a system focusing more on family services (e.g., 
Sweden, Denmark, Finland), although these differences are steadily disappearing with countries gradually assuming characteristics of each other's systems (Gilbert, 2012).

In addition to inter-countries differences in family support, there is much intracountry diversity regarding the resources used to assist at-risk families. On the one hand, in countries such as Spain, with regions with a high degree of economic autonomy, there are differences in the amount of economic resources invested in these services. On the other hand, diversity concerning conceptual assumptions and epistemological frameworks in the field of family support itself plus the diversification of services have led to differences in the types of intervention (e.g., psycho-educational, therapeutic, instrumental assistance), formats (e.g., group or individual), targets (e.g., parents, children or the whole family), and accessibility (universal, selected and indicated) (Berry \& McLean, 2014; Frost et al., 2015; Gordon, 1987). The empirical data available show that many programs for at-risk families combine educational components with information and guidance, in addition to the inclusion of financial assistance varying greatly. In turn, although most programs are preventive, the programs for at-risk families tend to be more selective than universal (Cavaleri, Olin, Kim, Hoagwood, \& Burns, 2011; Moran, Ghate, \& van der Merwe, 2004).

Beyond the analysis of the diversity of the existing resources, and to ensure the success of interventions, it is crucial for the support resources available for at-risk families to meet the quality standards of evidence-based programs. In this sense, there is a great deal of information available about the criteria that define the quality of these programs, in other words, how the programs of education and family support should be conducted to ensure the success of the interventions (e.g., Asmussen, 2011; Flay et al., 2005; Scott, 2010; Small, Cooney, \& O’Connor, 2009; Yarbrough, Shulha, Hopson, \& Caruthers, 2011). Firstly, there is broad agreement that programs should have an 
analysis of the needs and strengths of the target families, so that the objectives are as close as possible to the specific needs of the population the program was designed for (Molinuevo, 2013). Together with the needs analysis, a second quality criterion for family support programs is that they should have an explicit theoretical framework to explain how change occurs due to the intervention. The change model must explain how a significant improvement in the quality of life of the families is brought about after taking part in the program (Flay et al., 2005; Small et al., 2009). Furthermore, the theoretical framework underpinning a program ought to provide the foundation for its methodological proposal (Jiménez \& Hidalgo, 2016). Thirdly, the most distinctive criterion of evidence-based programs is that they have proven their effectiveness in rigorous evaluation studies. In program evaluation, quality criteria make clear that it is not enough to evaluate the overall efficacy of the interventions; instead they have to prove effectiveness and provide guarantees for their dissemination. To ensure a program's effectiveness, it needs to have demonstrated changes with an important effect-size using appropriate statistical analysis and robust assessment measures. In addition, the changes need to have been demonstrated using different external impact evaluations, including a group for comparison and with follow-up evaluations (Flay et al., 2005; Small et al., 2009). Finally, another feature of evidence-based programs is their quality implementation process. The most important elements of program implementation include institutional support, the training of practitioners, and flexibility and fidelity in the application of the program. To guarantee the fidelity in the implementation, it is essential for programs to be structured and to have a detailed manual laying down the objectives, contents and activities to be carried out which will enable the program to be delivered by people unfamiliar with its design (De Melo \& 
Alarcao, 2012; Durlak \& DuPre, 2008; Fixsen, Naoom, Blase, Friedman, \& Wallace, 2005). These quality standars are summarized in Table 1.

(Table 1 near here)

Although the quality standards for programs of family support and the promotion of positive parenting are well defined, many initiatives do not meet these criteria, particularly the services for at-risk families. Against this backdrop, this paper intends to provide an overview of services available for at-risk families in Spain. We propose two specific objectives: (1) identify and analyze different resources available for at-risk families; (2) analyze and assess the quality of programs promoting positive parenting currently being used with these families.

\section{Method}

\section{Procedure}

We conducted this study in two stages. Firstly, we identified and selected Spanish agencies offering family support services (social, education and health services) using an incidental sampling. We selected 24 agencies from all regions of Spain. 4 agencies showed no interest in the study and 4 agencies could not be contacted. Finally, 16 different agencies from 11 regions participated in the study, We contacted the responsible practitioner from each one who informed us about the services that these agencies offered to attend at-risk families. After identifying and analyzing the resources offered by each agency, we ended up with a total of 64 support services for at-risk families. We then interviewed the coordinators and practitioners responsible for the implementation of these resources for a detailed description of the family support services. With this information, we completed the form Characteristics of resources for at-risk families, which is outlined in the instruments section. 
In the second stage of the study, from the resources identified earlier we selected the programs that met the following inclusion criteria: 1) they were aimed at families with children at psychosocial risk; 2) they were psycho-educational; 3) they had some degree of structure (for example, having clear objectives) and 4) they had overall aim of promoting positive parenting. Having applied these criteria, we selected 20 programs promoting positive parenting for at-risk families. To obtain detailed information about the characteristics and quality of these programs we interviewed the practitioners who were responsible for their implementation and filled in the form with the Characteristics of the programs for the promotion of positive parenting for at-risk families, which is described in the instruments section.

\section{Analyzed resources and programs}

As mentioned above, we selected 16 agencies in the first stage of this study from different regions in Spain: Andalusia (3 agencies), Asturias (1 agency), Basque Country (1 agency), Canary Islands (1 agency), Castile-Leon (1 agency), Catalonia (2 agencies), Extremadura (1 agency), Galicia (1 agency), Madrid (2 agencies), Navarre (1 agency), Valencia ( 1 agency) and national (1 agency). These family support services were provided by different sectors: social services, education and health. They were also provided at different administrative levels (local, regional and national), and had diverse sources of funding (public, private and NGOs). Specifically, $68.8 \%(n=11)$ of these services were provided by the public sector, while $25 \%(n=4)$ were NGOs and one agency $(6.2 \%)$ was private. Most were related to the child welfare system $(56.3 \%, n=$ $9)$ or to the education system $(25 \%, n=4)$. Only $12.5 \%(n=2)$ of the services were in the health sector, and 6.2\% $(n=1)$ inter-sectorial. In territorial terms, $43.8 \%(n=7)$ of the services were provided by regional administrations, $50.0 \%(n=8)$ were local services, and $6.2 \%(n=1)$ were provided at a national level. 
From these services, 64 resources were aimed at supporting at-risk families. Of these 64 family support services, and following the above-mentioned inclusion criteria, we analyzed in greater depth the 20 structured programs that promoted positive parenting. The analysis and characteristics of the 64 family support services and the 20 positive parenting promotion programs will be presented in the results section.

\section{Instruments}

To collect the information, we used two instruments that were developed ad hoc for this study. Both were completed during the interviews with the practitioners and the coordinators responsible for the resources and programs.

Characteristics of resources for supporting at-risk families. In each of the selected agencies we collected information about all the support resources for at-risk families. The information collected in the form for each resource included: the type of agency (public, private, NGO), the territorial level (local, regional, national), the sector

applying the intervention (social services, education or health), the type of coverage and accessibility (universal, selective and indicated), the target population (parents, children or the whole family), the type of intervention (psycho-educational, therapeutic, economical, etc.), the modality (group, individual or community), the stability of the intervention, the background of the professionals implementing the program and the origin of funding.

Characteristics of positive parenting programs for at-risk families. This second form was completed for a more detailed analysis of those resources, which were structured programs promoting positive parenting for families at psychosocial risk. The form collected information about the following aspects: the existence of a theoretical framework and change model, the relation between the adopted methodology and the theoretical framework of reference, the explicit description of program objectives, the 
existence of a previous needs analysis, the existence of planned activities, and the quality of program evaluation.

\section{Results}

The following section presents the results obtained in the two stages of the study. Firstly, we present the results of the analysis of the 64 family support resources identified in the first stage for the care of at-risk families. We then present the results of the analysis of the 20 programs selected from the above resources that had a psychoeducational approach and their overall objective was to promote positive parenting.

\section{Support services for at-risk families}

Although most of the 64 family support services analyzed in this study included between 2 and 4 different intervention modalities (see Figure 1), psycho-educational interventions were present in most of the resources analyzed $(53.1 \%, n=34)$.

(Figure 1 near here)

The accessibility of the family support services varied. According to the Gordon's (1987) classification of programs, 17.2\% $(n=11)$ of the resources were universal (in other words, accessible for any person or family); in $42.2 \%(n=27)$ of cases the access to resources was selective (for groups with specific characteristics); and in $40.6 \%(n=26)$ of cases, the access was indicated (access to services required referral by a practitioner).

The analysis of family support services highlighted that $23.4 \%(n=15)$ of resources were aimed at a specific population group, and access to $18.8 \%(n=12)$ was means tested (family income below a certain level). In turn, 35.9\% $(n=23)$ of the interventions analyzed were aimed specifically at families at low-medium risk, and $39.1 \%(n=25)$ of resources were aimed exclusively at high-risk families. 
The analyzed family support services were individual interventions on $31.3 \%$ of occasions $(n=20)$, group interventions in $29.7 \%$ of cases $(n=19)$ and a combination of both in $25 \%(n=16)$. The family support services were normally aimed at the family as a whole $(40.6 \%, n=26)$, or to parents $(34.4 \%, n=22)$, while it was less common for interventions to be aimed specifically at children.

Most of the resources analyzed were stable over time $(92.2 \%, n=59)$ and mainly applied systematic interventions $(78.1 \%, n=50)$. Intervention implementation was down to the service practitioners in more than half of the cases $(51.6 \%, n=33)$; in $31.3 \%$ of the resources $(n=20)$ the interventions were applied by external technicians, and in $17.2 \%(n=11)$ interventions were conducted by internal and external practitioners.

The funding of the family support measures was stable in $90.6 \%(n=58)$ of the cases. Specifically, in $89.1 \%$ of the cases $(n=57)$ the financial resources sustaining the interventions came from the actual budgets of the service, while $21.9 \%(n=14)$ of the measures benefited from external public funding, and $9.4 \%(n=6)$ of the interventions were funded privately. Table 2 shows the previous indicators broken down according to the type of intervention present in the family support resources analyzed.

(Table 2 near here)

\section{Positive parenting programs for at-risk families}

In terms of the agencies applying the 20 positive parenting programs, most were run by the social services $(80 \%, n=16)$, with two implemented by education centers, one by health agency and the last was inter-sectorial. The programs were implemented mostly by local agencies $(50 \%, n=10)$ and regional ones $(45 \%, n=9)$; and only one program depended on national institution. Although the psycho-educational character was an inclusion criterion and therefore all the interventions had an element of this 
component, those programs which were exclusively psycho-educational represented $45 \%(n=9)$ of the total. Those that also included a therapeutic component constituted $40 \%(n=8)$ of the programs analyzed, those which were psycho-educational and assistance-based represented $10 \%(n=2)$, and only one program was defined as psychoeducational and promoting healthy use of leisure and free time (5\%). All of the analyzed programs were designed in Spain.

We analyzed the characteristics of these programs in depth to assess how far the programs complied with the quality standards for this type of interventions. On one hand, in their conceptual frameworks, roughly half of the programs $(n=9)$ included models about the functioning of families in contexts of risk and a description of the change model. Likewise, in $60 \%(n=12)$ of the programs there was a strong relation between the methodology used and the theoretical frameworks of reference for the program. In terms of structuring, the results showed that $35 \%(n=7)$ of the programs did not have planned activities. This average level of structuring was also reflected in terms of manualization for the program: only half of the programs analyzed $(n=10$, $50 \%$ ) had a manual that would allow someone with no previous experience of the program to apply said program. However, in 30\% $(n=6)$ of these programs the manuals were so vague that it would have been impossible to implement the program using the written documentation. In the remaining $20 \%(n=4)$, there was no manual.

As an explicit description of the objectives was an inclusion criterion for the second phase of the study, this was fully present in $100 \%(n=20)$ of the programs. We found five main objectives: (a) the promotion of emotional, social and cognitive development of both children and parents $(60 \%, n=12)$; (b) the improvement of positive parenting through the development of parental skills and competencies $(55 \%, n$ $=11$ ); (c) the promotion of family community integration, support networks and healthy 
leisure time $(50 \%, n=10)$; (d) the improvement of the climate within the family and family relations, particularly parent-child $(45 \%, n=9)$; and (e) the facilitation of children's adaptation at school, from prevention of truancy to providing extra tutorial sessions $(30 \%, n=6)$. In $85 \%(n=17)$ of the cases, the objectives stemmed from the needs analysis prior to the intervention and to a great extent $(82,4 \%, n=12)$ they met these needs. As for the quality of these needs studies, only $17.6 \%(n=3)$ conducted a rigorous analysis of needs, $35.3 \%(n=6)$ had performed an analysis of average rigor and $47.1 \%(n=8)$ of the programs analyzed had been designed based on needs studies lacking in rigor.

Finally, we analyzed the quality of program evaluation. Data showed that $75 \%$ $(n=15)$ of the programs had been evaluated. These were effectiveness evaluation in all cases; and more than half implementation evaluation $(60 \%, n=12)$. In most cases the evaluations were internal $(65 \%, n=13$, ), followed by external $(20 \%, n=4)$ and then mixed designs $(15 \%, n=3)$. The average number of evaluation studies performed over the years of program implementation was roughly five $(M=4.70, D T=8.02)$, but with very broad variability $($ minimum $=0$, maximum $=33$ studies $)$. Most of the evaluations did not use a pretest-postest design $(n=12.60 \%)$ nor did they include a control group with similar characteristics to compare to the participant group $(n=15.75 \%)$. Similarly, none of the programs used randomization to form the control group. As for the followup of participants after program completion, some programs $(n=7.35 \%)$ performed at least one assessment months later, while the majority did not mention any follow-up ( $n$ $=13.65 \%)$.

\section{Discussion}

The aim of this article was to analyze different support resources in Spain for atrisk families, paying special attention to the quality of the programs promoting positive 
parenting. In the following section, we shall discuss the results obtained in the two stages of the study together, focusing firstly on the characteristics of the family support services and then analyzing the extent to which they meet the quality criteria for evidence-based programs.

The analysis of the characteristics of the family support services highlighted that, in general, they are mainly selective psycho-educational interventions which are specific for at-risk families and consist of individual work with the family, particularly with the parents. These interventions are normally run by public local social services and have a high level of stability. This picture of support services for at-risk families has many similarities but also some differences compared to those of other European countries (Boddy et al., 2009; Boddy et al., 2011; ChildOnEurope, 2007; Janta, 2013; Molinuevo, 2013). On one hand, in terms of the most usual type of intervention, the prevalence of psycho-educational components coincides with the results of different reviews on the main characteristics of family support initiatives (Cavaleri et al., 2011). This was to be expected as the Recommendation Rec(2006)19 emphasized the need for psycho-educational family support interventions promoting positive parenting (Council of Europe, 2006). The fact that many of the resources and programs analyzed combined several types of intervention (i.e., programs promoting positive parenting with psychoeducational and therapeutic components) underlines that Spain is part of one of the trends mentioned in the introduction: the need to attune interventions to specific family needs (Moran et al., 2004). Thus, from what we know about the profile of at-risk families, they often have needs related to educational skills but also others related to personal development and adjustment, which would explain the combination we found of psycho-educational and therapeutic components. 
On the other hand, in terms of access to resources, most interventions were selective. Although we found a common ground with other reviews on this point (Cavaleri et al., 2011), it remains unclear whether this constitutes the most adequate form of delivery. As Rodrigo et al. (2016) stated, the best way to deliver parental support to at-risk families is in a non-stigmatizing way. One way of achieving this is through universal group interventions with a heterogeneous make-up. In other words, participants including at-risk families and as well as other non-at-risk families from the same neighborhood, facilitating the emergence of informal support networks and promoting community integration. However, as the results showed, group interventions are not yet the most usual type of support services for at-risk families, despite their clear benefits (Yalom \& Leszcz, 2005).

Finally, the results about the characteristics of the family support services showed that the vast majority of interventions were delivered by public and local social welfare agencies. This was to be expected for two reasons: firstly, Spain has a solid public welfare system for supporting at-risk families; second, in keeping with European recommendations, these services should be delivered by the institutions that are the closest to their citizens (Council of Europe, 2011). The fact that family support resources are delivered by local agencies is similar to what occurs in other countries. However, in Spain there are very few initiatives promoting positive parenting delivered by the health agencies, while in other countries there is already a long history of family support delivered by this sector (Hoagwood et al., 2010). These results allow us to conclude that Spain must strengthen its healthcare network to cope with the severe situation of poverty and exclusion in which many families live (CES, 2017).

The quality analysis of the positive parenting promotion programs found an average level of compliance with the standards of evidence-based programs. In terms of 
manualization, half the programs analyzed had no manual at all, and when they did have one, it did not always contain the information that would be necessary for its delivery by people who were unfamiliar with its design. This has a negative effect on the implementation process, making fidelity (which is considered central to intervention success) more difficult (Durlak \& DuPre, 2008; Fixsen et al., 2005). Likewise, only half the programs had a solid theoretical base, including the model of change. The inclusion of a model explaining how change occurs or improvement after the intervention is a question of great importance. The absence of a theoretical model obstructs both an implementation that is faithful to the original design and the task of discerning which procedures or methodologies favor change in the family (Jiménez \& Hidalgo, 2016; Small et al., 2009).

The results demonstrated the existence of needs analysis, which provided the basis for the establishment of the intervention objectives in most of the positive parenting promotion programs analyzed. This constitutes a strength because it enables to "personalize" the interventions to meet the specific needs of the population (Moran et al., 2004). As we mentioned earlier, the objectives tackled in the interventions included both the promotion of parental and personal competencies, and the improvement in family dynamics and community integration. These contents underline that in Spain the objective of interventions for at-risk families has changed significantly. The focus is no longer placed exclusively on child protection, instead it now aims to promote the wellbeing of all family members, through community-based interventions with the emphasis on prevention and family support in a more global sense, including from economic aid to parenting education programs (Rodrigo et al., 2016).

Finally, the results concerning program evaluation reveal the main weakness of the family support initiatives analyzed in this study. Not all the programs were 
evaluated and, when they were, the evaluation studies were not always comprehensive and rigorous. The most frequent were efficacy evaluations that did not include a control group and seldom included a follow-up. Bearing in mind that rigorous evaluation is included in quality guidelines, the results showed that most of the interventions could not be considered evidence-based programs (Flay et al., 2005). Although the low social spending per capita in Spain could explain this fact, this limitation really is not exclusive to Spanish programs and making all family support interventions comply with the assessment standards of evidence-based programs still constitutes a challenge for most European countries (Asmussen, 2011; Scott, 2010). Although there is no doubt that evaluation is required to demonstrate that interventions really produce benefits in families, we should not forget that experimental studies with a randomly assigned control group do not constitute the only valid program evaluation option. In an alternative stance, several experts in family support program evaluation are questioning the utility and ethical viability of these designs; instead they defend a more plural vision of assessment that does not just consider methodological adequacy, but also its ethical utility, viability and ethical rigor (e.g., Boddy et al., 2011; Moran et al., 2004; Yarbrough et al., 2011).

In recent years, we have seen an accumulation of evidence about the delivery of family support in some European countries. However, as far as we know, this is the first study providing information about different resources and programs existing in Spain that are aimed specifically for at-risk families. The study does have a number of limitations: the number of agencies which identified resources and programs was small given the size of Spain, Therefore, the obtained results need to be confirmed in studies with greater territorial representativeness.. In addition, rather than just including characteristics of the programs, we would also have liked to include their results in the 
analysis. Despite these limitations, this paper offers an overview of different family support initiatives that are currently available in some regions of Spain to at-risk families. The results show that these resources take the form of national programs of a psycho-educational nature which are normally designed to meet the specific needs of their target population. They are usually delivered by local public social services. The main drawback with these Spanish interventions is the lack of rigorous evaluation.

In the light of these results, certain practical conclusions can be drawn in terms of the policies and service provision for families in situations of psychosocial risk. Given the need for diversification of services and progressive universalism, initiatives of family support should include a mixture of services, while always ensuring that interventions meet the specific needs of the families they are helping (Molinuevo, 2013; Rodrigo et al., 2016). Therefore, family support services need to be diversified in terms of delivery, with more initiatives from education and health agencies. Moreover, preventive initiatives should be enhanced, as they are the most effective and least stigmatizing form of delivery (Haggerty \& Shapiro, 2013). Despite the progress made in interventions supporting at-risk families, an evidence-based approach remains a challenge for Spanish programs. To overcome difficulties in this area, there need to be rigorous program evaluations while they are being implemented to be able to identify what works, for whom and under what circumstances. Apart from being rigorous, the program evaluations also need to be useful, feasible, suitable and accountable (Yarbourgh et al., 2011).

Consensus is needed regarding the skills and qualifications of the family support workforce to ensure quality performance when attending families (Durlak \& DuPre, 2008). Hence, progress is required to make available the best training practices for practitioners working in this field (Long, 2016). As other papers in this volume have 
mentioned, the extent to which national policies on family support opt for and include initiatives promoting good practices and positive parenting will determine whether the resources for at-risk families fulfil their ultimate objective: ensuring the wellbeing and encouraging the development of the children growing up in these family contexts.

\section{References}

Asmussen, K. (2011). The evidence-based parenting practitioner's handbook. New York: Routledge.

Berry, M., \& McLean, S. (2014). Family preservation. In G. P. Mallon, \& P. M. Hess (Eds.), Child welfare for the twenty-first century. A handbook of practices, policies, and programs (pp. 270-287). New York: Columbia University Press.

Boddy, J., Smith, M., \& Statham, J. (2011). Understandings of efficacy: Cross-national perspectives on 'what works' in supporting parents and families. Ethics and Education, 6(2), 181-196.

Boddy, J., Statham, J., Smith, M., Ghate, D., Wigfall, V., \& Hauari, H. (2009). International perspectives on parenting support: Non-English language sources DCSF Research Report No DCSF-RR 114. London: Institute of Education, University of London. Retrieved from https://core.ac.uk/download/pdf/8768799.pdf

Bornstein, M. H. (2015). Children's parents. In M. H. Bornstein \& T. Leventhal (Eds.), Handbook of Child Psychology and Developmental Science: Vol. 4. Ecological Settings and Processes (pp. 55-132). New Jersey: Wiley.

Brooks, J. (2004). The process of Parenting. New York: McGraw Hill. 
Cavaleri, M. A., Olin, S. S., Kim, A., Hoagwood, K. E., \& Burns, B. J. (2011). Family support in prevention programs for children at risk for emotional/behavioural problems. Clinical Child Family Psychology Review, 14(4), 399-412.

CES (2017). Informe Politicas Públicas para combatir la pobreza en España. Madrid: Consejo Económico y Social.

Chaffin, M., Bonner, B. L., \& Hill, R. F. (2001). Family preservation and family support programs: child maltreatment outcomes across client risk levels and program types. Child Abuse \& Neglect, 25(10), 1269-1289.

ChildOnEurope (2007). Survey on the role of parents and the support from the Governments in the EU. Strasbourg: Council of Europe Publications. Retrieved from http://www.childoneurope.org/activities/pdf/reportSurveyRoleParents

Council of Europe (2006). Recommendation Rec(2006)19 of the Committee of Ministers to members states on policy to support positive parenting. Retrieved from http://www.coe.int/es

Council of Europe (2011). Recommendation Rec(2011)12 of the Committee of Ministers to member states on children's rights and social services friendly to children and families. Retrieved from http://www.coe.int/es

Daly, M. (2007). Parenting in contemporary Europe: A positive approach. Strasbourg: Council of Europe Publishing.

Daly, M., Bray, R., Byrne, J., Bruckauf, Z., Margaria, A., Pecnik, N., \& SammsVaughan, M. (2015) Family and Parenting Support Policy and Provision in a Global Context. Florence: UNICEF.

De Melo, A. T., \& Alarcao, M. (2012). Implementation of a Community-based Familycentred program in Portugal: a multiple case study evaluation. Journal of Community Psychology, 40(6), 665-680. 
Durlak, J. A., \& DuPre, E. P. (2008). Implementation matters: A review of research on the influence of implementation on program outcomes and the factors affecting implementation. American Journal of Community Psychology, 41(3-4), 327-350.

Fine, M. A., \& Fincham, F. D. (2013). The role of theory in family science. In M. A. Fine \& F. D. Fincham (Eds.), Handbook of Family Theories. A Content-Based Approach (pp. 1-10). New York: Routledge.

Fixsen, D. L., Naoom, S., F., Blase, K. A., Friedman, R. M., \& Wallace, F. (2005). Implementation research: A synthesis of the literature. Tampa, FL: University of South Florida, Louis de la Parte Florida Mental Health Institute, The National Implementation Research Network.

Flay, B., Biglan, A., Boruch, R. F., Castro, F. G., Gottfredson, D., Kellam, S., ... Ji, P. (2005). Standards of evidence: Criteria for efficacy, effectiveness and dissemination. Prevention Science, 6(3), 151-175.

Fraser, M. W., \& Galinsky, M. J. (2004). Risk and resilience in childhood: Toward and evidence-based model of practise. In M.W. Fraser (Ed.), Risk and resilience in childhood: An ecological perspective (2nd ed., pp. 385-402). Washington, D.C: NASW Press.

Frost, N., Abbott, S., \& Race, T. (2015): Family support. Cambridge: Polity.

Gilbert, N. (2012). A comparative study of child welfare systems: Abstract orientations and concrete results. Children and Youth Services Review, 34(3), 532-536.

Gordon, R. (1987). An operational classification of disease prevention. In J. A. Steinberg, \& M. M. Silverman (Eds.) Preventing mental disorders (pp. 20-26). Rockville, MD: Department of Health and Human Services. 
Haggerty, K. P., \& Shapiro, V. B. (2013). Science-based prevention through communities that care: A model of social work practice for public health. Social Work in Public Health, 28(3-4), 349-365.

Hoagwood, K. E., Cavaleri, M., Olin, S. S., Burns, B. J., Slaton, E., Gruttadaro, J. D., \& Hughes, R. (2010). Family support in children's mental health: A review and synthesis. Clinical Child and Family Psychology Review, 13(1), 1-45.

Janta, B. (2013). Parenting support policy brief. Santa Monica: RAND.

Jiménez, L., \& Hidalgo, M. V. (2016). La incorporación de prácticas basadas en evidencias en el trabajo con familias: los programas de promoción de parentalidad positiva. [Incorporating evidence-based practices into work with families: programmes to promote positive parenting] Apuntes de Psicología, $34(2-3), 91-100$.

Long, N. (2016). Future trends in parenting education. In J. Ponzetti (Ed). Evidencebased parenting education: A global perspective (pp. 311-328). New York: Routledge.

Molinuevo, D. (2013). Parenting support in Europe. Dublin: Eurofound.

Moran, P., Ghate, D., \& van der Merwe, A. (2004) What Works in Parenting Support? A Review of the International Evidence. Nottingham: Department for Education and Skills Policy Research Bureau.

Patterson, G. R., Chamberlain, P., \& Reid, J. B. (2016). A Comparative Evaluation of a Parent-Training Program - Republished Article. Behavior Therapy, 47(6), 804811.

Rodrigo, M. J., Almeida, A., \& Reichle, B. (2016). Evidence-based parent education programs: A European perspective. In J. Ponzetti (Ed). Evidence-based parenting education: A global perspective (pp. 85-104). New York: Routledge. 
Rodrigo, M. J., Byrne, S., \& Álvarez, M. (2012). Preventing child maltreatment through parenting programmes implemented at the local social services level. European Journal of Developmental Psychology, 9(1), 89-103.

Rodrigo, M. J., Máiquez, M. L., Martín, J. C., \& Byrne, S. (2008). Preservación familiar. Un enfoque positivo para la intervención con familias. Madrid: Pirámide.

Scott, S. (2010). National dissemination of effective parenting programmes to improve child outcomes. The British Journal of Psychiatry, 196(1), 1-3.

Small, S. A., Cooney, S. M., \& O’Connor, C. (2009). Evidence-informed program improvement: Using principles of effectiveness to enhance the quality and impact of family-based prevention programs. Family Relations, 58(1), 1-13.

Spoth, R., \& Redmond, C. (2000). Research on family engagement in preventive interventions: Toward improved use of scientific findings in primary prevention practice. The Journal of Primary Prevention, 21(2), 267-284.

United Nations (1989). Convention on the Rights of the Child. Retrieved from http://www.ohchr.org/EN/ProfessionalInterest/Pages/CRC.aspx

Yalom, I. D., \& Leszcz, M. (2005). The theory and practice of group psychotherapy (5th ed.). New York: Basic Books.

Yarbrough, D. B., Shulha, L. M., Hopson, R. K., \& Caruthers, F.A. (2011). The program evaluation standards (3rd ed.). California: Sage. 


\section{Table 1}

Quality standards for support parenting programs

Needs assessment

Theoretical framework

Evaluation research
Objectives tailored to the needs of families

Explicit change model

Foundation for methodological proposal

External evaluations

Control group

Design with pretest, posttest and follow up

Standardized measuring instruments

Rigorous statistical analyses (effect size, significance indicators, etc.)

Detailed Manual

Institutional support

Training of practitioners

Flexibility and fidelity in the application of the program or the intervention 
Figure 1

Type of intervention of support services for at-risk families.

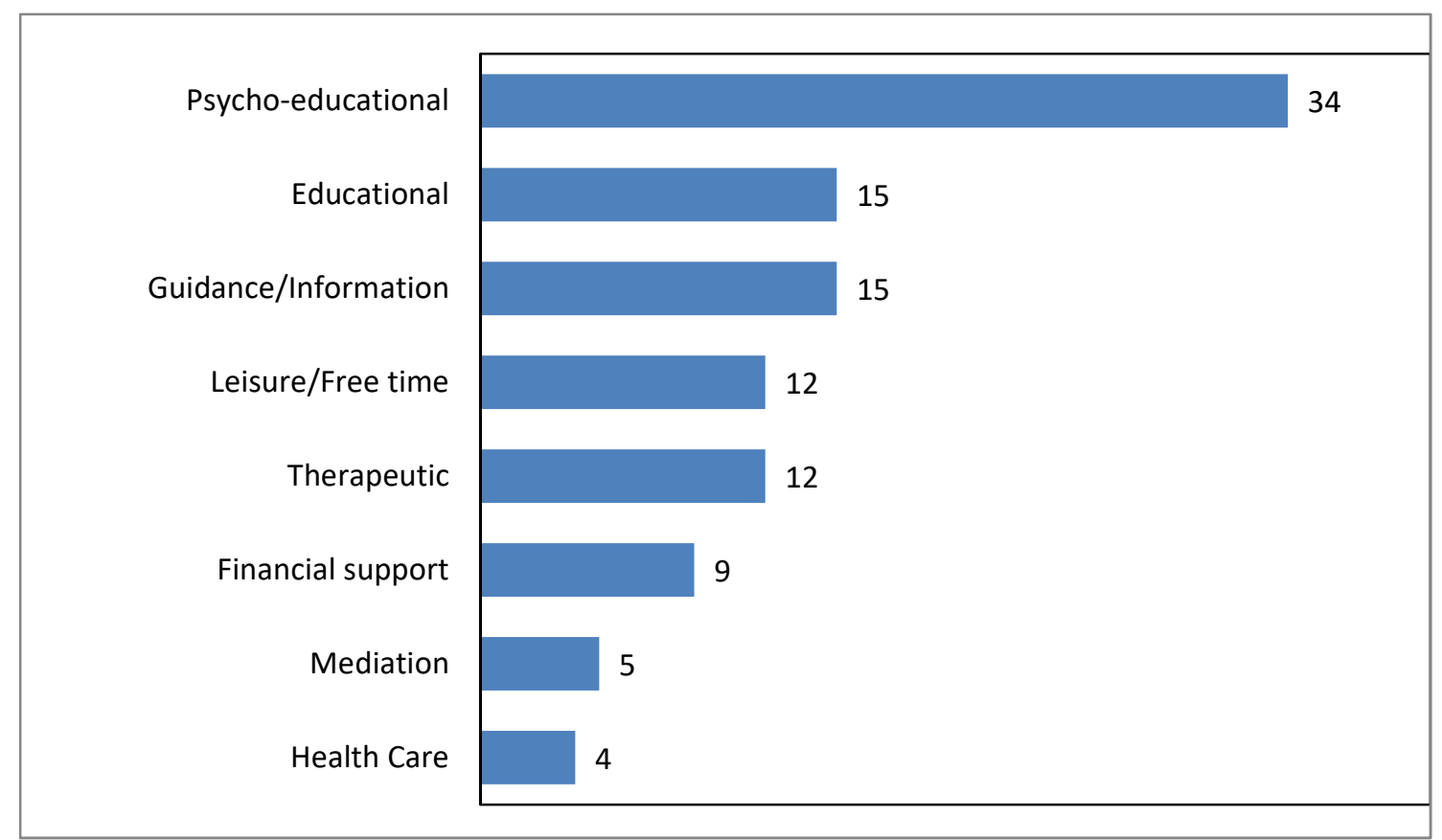




\section{Table 2}

Characteristics of the family support services analyzed according to the type of intervention.

\begin{tabular}{|c|c|c|c|c|c|c|c|c|}
\hline & & Psycho-educational & Therapeutic & Mediation & Educational & Leisure & Guidance & Health care \\
\hline \multirow[b]{2}{*}{ Access } & Universal & $5.9 \%$ & --- & $20 \%$ & $33.3 \%$ & $33.3 \%$ & $26.7 \%$ & $50 \%$ \\
\hline & Selective & $47.1 \%$ & $25 \%$ & $60 \%$ & $20 \%$ & $33.3 \%$ & $46.7 \%$ & $25 \%$ \\
\hline \multicolumn{9}{|c|}{ Target group/s (non-exclusive): } \\
\hline \multirow{2}{*}{\multicolumn{2}{|c|}{$\begin{array}{l}\text { - Universal } \\
\text { - Specific groups }\end{array}$}} & $8.8 \%$ & --- & $20 \%$ & $33.3 \%$ & $33.3 \%$ & $26.7 \%$ & $50 \%$ \\
\hline & & $26.5 \%$ & $16.7 \%$ & $20 \%$ & $13.3 \%$ & $25 \%$ & $33.3 \%$ & $25 \%$ \\
\hline \multicolumn{2}{|c|}{ - Means tested } & $17.6 \%$ & $16.7 \%$ & --- & $26.7 \%$ & $25 \%$ & $26.7 \%$ & $25 \%$ \\
\hline - Low-r & lium risk & $55.9 \%$ & $50 \%$ & $40 \%$ & $40 \%$ & $50 \%$ & $33.3 \%$ & --- \\
\hline \multicolumn{2}{|c|}{$\begin{array}{l}\text { - Low-medium risk } \\
\text { - High risk }\end{array}$} & $44.1 \%$ & $91.7 \%$ & $20 \%$ & $40 \%$ & $33.3 \%$ & $20 \%$ & $25 \%$ \\
\hline \multirow{5}{*}{ Targets } & Children & $11.8 \%$ & $\begin{array}{c}-- \\
\end{array}$ & $20 \%$ & $53.3 \%$ & $50 \%$ & $-\overline{---}$ & $25 \%$ \\
\hline & Adolescents & --- & $8.3 \%$ & --- & $6.7 \%$ & $8.3 \%$ & --- & --- \\
\hline & Minors & --- & --- & --- & $6.7 \%$ & $8.3 \%$ & --- & --- \\
\hline & Adults & $35.3 \%$ & $8.3 \%$ & $60 \%$ & $13.3 \%$ & $8.3 \%$ & $53.3 \%$ & $75 \%$ \\
\hline & Family & $52.9 \%$ & $83.3 \%$ & $20 \%$ & $20 \%$ & $25 \%$ & $46.7 \%$ & --- \\
\hline \multirow{3}{*}{ Modality } & Individual & $20.6 \%$ & $50 \%$ & $100 \%$ & $\begin{array}{l}-- \\
--\end{array}$ & $\begin{array}{l}-- \\
--\end{array}$ & $20 \%$ & $25 \%$ \\
\hline & Individual and group & $32.4 \%$ & $33.3 \%$ & --- & $40 \%$ & $33.3 \%$ & $26.7 \%$ & $25 \%$ \\
\hline & Mixed & $8.8 \%$ & --- & --- & $13.3 \%$ & $8.3 \%$ & $6.7 \%$ & $25 \%$ \\
\hline \multicolumn{2}{|l|}{ Stability } & $91.2 \%$ & $100 \%$ & $80 \%$ & $100 \%$ & $91.7 \%$ & $86.7 \%$ & $100 \%$ \\
\hline \multicolumn{2}{|l|}{ Consistency } & $79.4 \%$ & $66.7 \%$ & $60 \%$ & $80 \%$ & $75 \%$ & $53.3 \%$ & $100 \%$ \\
\hline \multirow{3}{*}{ Practitioners } & External & $20.6 \%$ & $33.3 \%$ & $60 \%$ & $53.3 \%$ & $50 \%$ & $26.7 \%$ & $25 \%$ \\
\hline & Int. and external & $11.8 \%$ & --- & --- & $20 \%$ & $16.7 \%$ & $20 \%$ & --- \\
\hline & Internal & $67.6 \%$ & $66.7 \%$ & $40 \%$ & $26.7 \%$ & $33.3 \%$ & $53.3 \%$ & $75 \%$ \\
\hline \multicolumn{2}{|c|}{ Stable funding } & $58.3 \%$ & $100 \%$ & $100 \%$ & $100 \%$ & $100 \%$ & $100 \%$ & $100 \%$ \\
\hline
\end{tabular}




\begin{tabular}{|c|c|c|c|c|c|c|c|}
\hline $\begin{array}{l}\text { Type(s) of funding (non-exclusive): } \\
\text { - Own } \\
\text { - External public } \\
\text { - External private }\end{array}$ & $\begin{array}{l}82.4 \% \\
23.5 \% \\
14.7 \%\end{array}$ & $\begin{array}{c}75 \% \\
58.3 \% \\
16.7 \%\end{array}$ & $\begin{array}{c}100 \% \\
40 \% \\
---\end{array}$ & $\begin{array}{c}93.3 \% \\
6.7 \% \\
20 \%\end{array}$ & $\begin{array}{c}91.7 \% \\
8.3 \% \\
16.7 \%\end{array}$ & $\begin{array}{c}100 \% \\
33.3 \% \\
13.3 \%\end{array}$ & $\begin{array}{c}100 \% \\
25 \% \\
---\end{array}$ \\
\hline
\end{tabular}

